\title{
Dynamic Analysis of Complex Synchronization Schemes between Integer Order and Fractional Order Chaotic Systems with Different Dimensions
}

\author{
Adel Ouannas, ${ }^{1}$ Xiong Wang, ${ }^{2}$ Viet-Thanh Pham, ${ }^{3}$ and Toufik Ziar ${ }^{4,5}$ \\ ${ }^{1}$ Laboratory of Mathematics, Informatics and Systems (LAMIS), University of Larbi Tebessi, 12002 Tebessa, Algeria \\ ${ }^{2}$ Institute for Advanced Study, Shenzhen University, Shenzhen, Guangdong 518060, China \\ ${ }^{3}$ Hanoi University of Science and Technology, Hanoi, Vietnam \\ ${ }^{4}$ Department of Matter Sciences, University of Larbi Tebessi, Tebessa, Algeria \\ ${ }^{5}$ Active Devices and Materials Laboratory (LCAM), Larbi Ben M'hidi University, Oum El Bouaghi, Algeria \\ Correspondence should be addressed to Viet-Thanh Pham; pvt3010@gmail.com
}

Received 15 February 2017; Revised 18 April 2017; Accepted 31 May 2017; Published 28 June 2017

Academic Editor: Delfim F. M. Torres

Copyright (C) 2017 Adel Ouannas et al. This is an open access article distributed under the Creative Commons Attribution License, which permits unrestricted use, distribution, and reproduction in any medium, provided the original work is properly cited.

\begin{abstract}
We present new approaches to synchronize different dimensional master and slave systems described by integer order and fractional order differential equations. Based on fractional order Lyapunov approach and integer order Lyapunov stability method, effective control schemes to rigorously study the coexistence of some synchronization types between integer order and fractional order chaotic systems with different dimensions are introduced. Numerical examples are used to validate the theoretical results and to verify the effectiveness of the proposed schemes.
\end{abstract}

\section{Introduction}

Nature is intrinsically nonlinear. So, it is not surprising that most of the systems we encounter in the real world are nonlinear. And what is interesting is that some of these nonlinear systems can be described by fractional order differential equations which can display a variety of behaviors including chaos and hyperchaos [1-5]. Recently, study on synchronization of fractional order chaotic systems has started to attract increasing attention of many researchers [6-12], since the synchronization of chaotic systems with integer order is understood well and widely explored [13-15]. Many scientists who are interested in the field of chaos synchronization have struggled to achieve the synchronization between integer order and fractional order chaotic systems.

At present, many schemes of control have been proposed to study the problem of synchronization between integer order and fractional order chaotic systems such as anticipating synchronization [16], function projective synchronization [17], complete synchronization [18], antisynchronization [19],
Q-S synchronization [20], and generalized synchronization [21]. Also, different techniques have been introduced to synchronize integer order and fractional order chaotic systems. For example, a nonlinear feedback control method has been introduced in [22]. The idea of tracking control has been applied in [23, 24]. In [25], general control scheme has been described. A new fuzzy sliding mode method has been proposed in [26], and a sliding mode method has been designed in $[27,28]$. Synchronization of a class of hyperchaotic systems has been studied in [29]. A practical method, based on circuit simulation, has been presented in [30], and in [31] a robust observer technique has been tackled.

Complete synchronization (CS), projective synchronization (PS), full state hybrid function projective synchronization (FSHFPS), and generalized synchronization (GS) are effective approaches to achieve synchronization and have been used widely in integer order chaotic systems [32-35] and fractional order chaotic systems [36-39]. Studying inverse problems of synchronization is an attractive and important idea. Recently, some interesting types of synchronization have 
been introduced such as inverse projective synchronization (IPS) [40], inverse full state hybrid projective synchronization (IFSHPS) [41], inverse full state hybrid function projective synchronization (IFSHFPS) [42], and inverse generalized synchronization (IGS) [43]. Coexistence of several types of synchronization produces new complex type of chaos synchronization. Not long ago, many approaches for the problem of coexistence of synchronization types have been proposed in discrete time chaotic systems, integer order chaotic systems, and fractional order chaotic systems [4447]. The coexistence of different type of synchronization is very useful in secure communication and chaotic encryption schemes.

This paper introduces new approaches to study the coexistence of some types of synchronization between integer order and fractional order chaotic systems with different dimensions. The new results, derived in this paper, are established in the form of simple conditions about the linear parts of the slave system and the master system, respectively, which are very convenient to verify. Using fractional Lyapunov approach, the coexistence of complete synchronization (CS), projective synchronization (PS), full state hybrid function projective synchronization (FSHFPS), and generalized synchronization (GS) between integer order master system and fractional order slave system is investigated. Based on integer order Lyapunov method, the coexistence of inverse projective synchronization (IPS), inverse full state hybrid function projective synchronization (IFSHFPS), and inverse generalized synchronization (IGS) between fractional order master system and integer order slave system is studied. The capability of the approaches is illustrated by numerical examples.

The rest of this paper is arranged as follows. Some theoretical bases of fractional calculus are introduced in Section 2. In Section 3, our main results of the paper are presented. In Section 4, our approaches are applied between some typical chaotic and hyperchaotic systems to show the effectiveness of the derived results. Section 5 is the conclusion of the paper.

\section{Theoretical Basis}

2.1. Fractional Integration and Derivative. There are several definitions of fractional derivatives $[48,49]$. The two most commonly used are the Riemann-Liouville and Caputo definitions. Each definition uses Riemann-Liouville fractional integration and derivatives of whole order. The difference between the two definitions is in the order of evaluation. The Caputo derivative is a time domain computation method [50]. In real applications, the Caputo derivative is more popular since the unhomogenous initial conditions are permitted if such conditions are necessary [51, 52]. Furthermore, these initial values are prone to measure since they all have idiographic meanings. The Riemann-Liouville fractional integral operator of order $q \geq 0$ of the function $f(t)$ is defined as

$$
J^{q} f(t)=\frac{1}{\Gamma(q)} \int_{0}^{t}(t-\tau)^{q-1} f(\tau) d \tau, \quad q>0, t>0 .
$$

Some properties of the operator $J^{q}$ can be found, for example, in [53]. In this study, Caputo definition is used and the fractional derivative of $f(t)$ is defined as

$$
\begin{aligned}
D_{t}^{p} f(t) & =J^{m-p}\left(\frac{d^{m}}{d t^{m}} f(t)\right) \\
& =\frac{1}{\Gamma(m-p)} \int_{0}^{t} \frac{f^{(m)}(\tau)}{(t-\tau)^{p-m+1}} d \tau,
\end{aligned}
$$

for $m-1<p \leq m, m \in \mathbb{N}, t>0$. The fractional differential operator $D_{t}^{p}$ is left-inverse (and not right-inverse) to the fractional integral operator $J^{p}$; that is, $D_{t}^{p} J^{p}=I$, where $I$ is the identity operator.

2.2. Lyapunov Stability for Integer Order Systems. Consider the following integer order system:

$$
\dot{X}(t)=F(X(t)),
$$

where $X(t)=\left(x_{1}(t), x_{2}(t), \ldots, x_{n}(t)\right)^{T}$ and $F: \mathbf{R}^{n} \rightarrow \mathbf{R}^{n}$.

Lemma 1 (see [54]). If there exists a positive definite Lyapunov function $V(X(t))$ such that $\dot{V}(X(t))<0$, for all $t>0$, then the trivial solution of system (3) is asymptotically stable.

2.3. Fractional Order Lyapunov Stability. Consider the following fractional order system:

$$
D_{t}^{p} X(t)=F(X(t)),
$$

where $X(t)=\left(x_{1}(t), x_{2}(t), \ldots, x_{n}(t)\right)^{T}, p$ is a rational number between 0 and 1 and $D_{t}^{p}$ is the Caputo fractional derivative of order $p$, and $F: \mathbf{R}^{n} \rightarrow \mathbf{R}^{n}$. For stability analysis of fractional order systems, a fractional extension of Lyapunov direct method has been proposed by the following theorem.

Theorem 2 (see [55]). If there exists a positive definite Lyapunov function $V(X(t))$ such that $D_{t}^{p} V(X(t))<0$, for all $t>0$, then the trivial solution of system (4) is asymptotically stable.

Now, we present a new lemma which is helpful in the proving analysis of the proposed method.

Lemma 3 (see [56]). $\forall t>0:(1 / 2) D_{t}^{p}\left(X^{T}(t) X(t)\right) \leq$ $X^{T}(t) D_{t}^{p}(X(t))$.

\section{Main Results}

3.1. Synchronization of Integer Oder Master System and Fractional Oder Slave System. The master system is defined by

$$
\dot{x}_{i}(t)=f_{i}(X(t)), \quad i=1,2,3,
$$

where $X(t)=\left(x_{1}(t), x_{2}(t), x_{3}(t)\right)^{T}$ is the state vector of the master system and $f_{i}: \mathbf{R}^{3} \rightarrow \mathbf{R}(i=1,2,3)$. We consider the slave system as

$$
D_{t}^{q} y_{i}(t)=\sum_{j=1}^{4} b_{i j} y_{j}(t)+g_{i}(Y(t))+u_{i}, \quad i=1,2,3,4,
$$


where $Y(t)=\left(y_{1}(t), y_{2}(t), y_{3}(t), y_{4}(t)\right)^{T}$ is the state vector of the slave system, $\left(b_{i j}\right) \in \mathbf{R}^{4 \times 4}, g_{i}: \mathbf{R}^{4} \rightarrow \mathbf{R}(i=1,2,3,4)$ are nonlinear functions, $0<q<1$, and $D_{t}^{q}$ is the Caputo fractional derivative of order $q$, and $u_{i}(i=1,2,3,4)$ are controllers.

Definition 4. We say that CS, PS, FSHFPS, and GS coexist in the synchronization of master system (5) and slave system (6), if there exist controllers $u_{i}(i=1,2,3,4)$ constant $\alpha \epsilon$ $\mathbf{R}^{*}-\{1\}$, differentiable functions $\beta_{j}(t): \mathbf{R}^{+} \rightarrow \mathbf{R}(j=1,2,3)$ and differentiable function $\varphi: \mathbf{R}^{3} \rightarrow \mathbf{R}$, such that the synchronization errors

$$
\begin{aligned}
& e_{1}(t)=y_{1}(t)-x_{1}(t), \\
& e_{2}(t)=y_{2}(t)-\alpha x_{2}(t), \\
& e_{3}(t)=y_{3}(t)-\sum_{j=1}^{3} \beta_{j}(t) x_{j}(t), \\
& e_{4}(t)=y_{4}(t)-\varphi(X(t))
\end{aligned}
$$

satisfy that $\lim _{t \rightarrow+\infty} e_{i}(t)=0, i=1,2,3,4$.

Error system (7), between master system (5) and slave system (6), can be differentiated as follows:

$$
\begin{aligned}
& D_{t}^{q} e_{1}(t)= \sum_{j=1}^{4} b_{1 j} y_{j}(t)+g_{1}(Y(t))+u_{1}-D_{t}^{q} x_{1}(t), \\
& D_{t}^{q} e_{2}(t)= \sum_{j=1}^{4} b_{2 j} y_{j}(t)+g_{2}(Y(t))+u_{2}-\alpha D_{t}^{q} x_{2}(t), \\
& D_{t}^{q} e_{3}(t)=\sum_{j=1}^{4} b_{3 j} y_{j}(t)+g_{3}(Y(t))+u_{3} \\
&-D_{t}^{q}\left[\sum_{j=1}^{3} \beta_{j}(t) x_{j}(t)\right], \\
& D_{t}^{q} e_{3}(t)= \sum_{j=1}^{4} b_{4 j} y_{j}(t)+g_{4}(Y(t))+u_{4} \\
&-D_{t}^{q}[\varphi(X(t))] .
\end{aligned}
$$

Error system (8) can be described as

$$
D_{t}^{q} e_{i}(t)=\sum_{j=1}^{4} b_{i j} e_{j}(t)+R_{i}+u_{i}, \quad i=1,2,3,4,
$$

where

$$
\begin{aligned}
& R_{1}=\sum_{j=1}^{4} b_{1 j}\left(y_{j}(t)-e_{j}(t)\right)+g_{1}(Y(t))-D_{t}^{q} x_{1}(t), \\
& R_{2}=\sum_{j=1}^{4} b_{2 j}\left(y_{j}(t)-e_{j}(t)\right)+g_{2}(Y(t))-\alpha D_{t}^{q} x_{2}(t),
\end{aligned}
$$

$$
\begin{aligned}
R_{3}= & \sum_{j=1}^{4} b_{3 j}\left(y_{j}(t)-e_{j}(t)\right)+g_{3}(Y(t)) \\
& -D_{t}^{q}\left[\sum_{j=1}^{3} \beta_{j}(t) x_{j}(t)\right], \\
R_{4}= & \sum_{j=1}^{4} b_{4 j}\left(y_{j}(t)-e_{j}(t)\right)+g_{4}(Y(t)) \\
& -D_{t}^{q}[\varphi(X(t))] .
\end{aligned}
$$

Rewrite error system (9) in the compact form

$$
D_{t}^{q} e(t)=B e(t)+R+U,
$$

where $D_{t}^{q} e(t)=\left[D_{t}^{q} e_{1}(t), D_{t}^{q} e_{2}(t), D_{t}^{q} e_{3}(t), D_{t}^{q} e_{4}(t)\right]^{T}, B=$ $\left(b_{i j}\right)_{4 \times 4}, R=\left(R_{i}\right)_{1 \leq i \leq 4}$, and $U=\left(u_{i}\right)_{1 \leq i \leq 4}$.

Theorem 5. There exists a suitable feedback gain matrix $C \in$ $\mathbf{R}^{4 \times 4}$ to realize the coexistence of CS, PS, FSHFPS, and GS between master system (5) and slave system (6) under the following control law:

$$
U=-R-C e(t) .
$$

Proof. Substituting (12) into (11), one can have

$$
D_{t}^{q} \mathrm{e}(t)=(B-C) e(t) .
$$

If a Lyapunov function candidate is chosen as $V(e(t))=$ $(1 / 2) e^{T}(t) e(t)$, then, the time Caputo fractional derivative of $V$ along the trajectory of system (13) is as follows:

$$
D_{t}^{q} V(e(t))=D_{t}^{q}\left(\frac{1}{2} e^{T}(t) e(t)\right),
$$

and using Lemma 3 in (14) we get

$$
D_{t}^{q} V(e(t)) \leq e^{T}(t) D_{t}^{q} e(t)=e^{T}(t)(B-C) e(t) .
$$

If we select the feedback gain matrix $C$ such that $B-C$ is a negative definite matrix, then we get $D_{t}^{q} V(e(t))<0$. From Theorem 2, the zero solution of system (13) is a globally asymptotically stable; that is, $\lim _{t \rightarrow+\infty} e_{i}(t)=0, i=1,2,3,4$. We conclude that master system (5) and slave system (6) are globally synchronized.

3.2. Synchronization of Fractional Oder Master System and Integer Oder Slave System. Now, the master system and the slave system can be described in the following forms:

$$
\begin{aligned}
D_{t}^{p_{i}} x_{i}(t) & =\sum_{i=1}^{3} a_{i j} x_{j}(t)+f_{i}(X(t)), \quad i=1,2,3, \\
\dot{y}_{i}(t) & =g_{i}(Y(t))+u_{i}, \quad i=1,2,3,4,
\end{aligned}
$$

where $X(t)=\left(x_{i}(t)\right)_{1 \leq i \leq 3}, Y(t)=\left(y_{i}(t)\right)_{1 \leq i \leq 4}$ are the states of the master system and the slave system, respectively, $D_{t}^{p_{i}}$ is the Caputo fractional derivative of order $p_{i}, 0<p_{i}<1$ ( $i=$ $1,2,3)$, and $\left(a_{i j}\right) \in \mathbf{R}^{3 \times 3}, f_{i}: \mathbf{R}^{3} \rightarrow \mathbf{R}(i=1,2,3)$, are nonlinear functions; for example, $g_{i}: \mathbf{R}^{4} \rightarrow \mathbf{R}(i=1,2,3,4)$ and $u_{i}(i=1,2,3,4)$ are controllers. 
Definition 6. We say that IPS, IFSHFPS, and IGS coexist in the synchronization of master system (16) and slave system (17); if there exist controllers $u_{i}(i=1,2,3,4)$ differentiable function $h(t): \mathbf{R}^{+} \rightarrow \mathbf{R}^{*}$, differentiable functions $\Lambda_{j}(t):$ $\mathbf{R}^{+} \rightarrow \mathbf{R}(j=1,2,3,4)$ and differentiable function $\phi: \mathbf{R}^{4} \rightarrow$ $\mathbf{R}$, such that the synchronization errors

$$
\begin{aligned}
& e_{1}(t)=x_{1}(t)-h(t) y_{1}(t), \\
& e_{2}(t)=x_{2}(t)-\sum_{j=1}^{4} \Lambda_{j}(t) y_{j}(t), \\
& e_{3}(t)=x_{3}(t)-\phi(Y(t))
\end{aligned}
$$

satisfy that $\lim _{t \rightarrow+\infty} e_{i}(t)=0, i=1,2,3$.

Error system (18), between master system (16) and slave system (17), can be derived as

$$
\begin{aligned}
& \dot{e}_{1}(t)=\dot{x}_{1}(t)-\dot{h}(t) y_{1}(t)-h(t) \dot{y}_{1}(t), \\
& \dot{e}_{2}(t)=\dot{x}_{2}(t)-\sum_{j=1}^{4} \dot{\Lambda}_{j}(t) y_{j}(t)-\sum_{j=1}^{4} \Lambda_{j}(t) \dot{y}_{j}(t), \\
& \dot{e}_{3}(t)=\dot{x}_{3}(t)-\sum_{j=1}^{4} \frac{\partial \phi}{\partial y_{j}} \dot{y}_{j} .
\end{aligned}
$$

Error system (19) can be written as

$$
\begin{aligned}
& \dot{e}_{1}(t)=\sum_{j=1}^{3} a_{1 j} e_{j}(t)+T_{1}-h(t) u_{1}, \\
& \dot{e}_{2}(t)=\sum_{j=1}^{3} a_{2 j} e_{j}(t)+T_{2}-\sum_{j=1}^{4} \Lambda_{j}(t) u_{j}, \\
& \dot{e}_{3}(t)=\sum_{j=1}^{3} a_{3 j} e_{j}(t)+T_{3}-\sum_{j=1}^{4} \frac{\partial \phi}{\partial y_{j}} u_{j},
\end{aligned}
$$

where

$$
\begin{aligned}
T_{1}= & \dot{x}_{1}(t)-\sum_{j=1}^{3} a_{1 j} e_{j}(t)-\dot{h}(t) y_{1}(t) \\
& -h(t) g_{1}(Y(t)), \\
T_{2}= & \dot{x}_{2}(t)-\sum_{j=1}^{3} a_{2 j} e_{j}(t)-\sum_{j=1}^{4} \dot{\Lambda}_{j}(t) y_{j}(t) \\
& -\sum_{j=1}^{4} \Lambda_{j}(t) g_{j}(Y(t)), \\
T_{3}= & \dot{x}_{3}(t)-\sum_{j=1}^{3} a_{3 j} e_{j}(t)-\sum_{j=1}^{4} \frac{\partial \phi}{\partial y_{j}} g_{j}(Y(t)) .
\end{aligned}
$$

Rewrite error system (20) in the compact form

$$
\dot{e}(t)=A e(t)+T-M \times \widehat{U}-u_{4} W,
$$

where $\dot{e}(t)=\left[\dot{e}_{1}(t), \dot{e}_{2}(t), \dot{e}_{3}(t)\right]^{T}, A=\left(a_{i j}\right)_{3 \times 3}, T=\left(T_{i}\right)_{1 \leq i \leq 3}$, $\widehat{U}=\left(u_{i}\right)_{1 \leq i \leq 3}, W=\left(0, \Lambda_{4}(t), \partial \phi / \partial y_{4}\right)^{T}$, and

$$
M=\left(\begin{array}{ccc}
h(t) & 0 & 0 \\
\Lambda_{1}(t) & \Lambda_{2}(t) & \Lambda_{3}(t) \\
\frac{\partial \phi}{\partial y_{1}} & \frac{\partial \phi}{\partial y_{2}} & \frac{\partial \phi}{\partial y_{3}}
\end{array}\right) .
$$

To achieve synchronization between systems (16) and (17), we assume that $M$ is an invertible matrix and $M^{-1}$ its inverse matrix. Hence, we have the following result.

Theorem 7. IPS, IFSHFPS, and IGS coexist between master system (16) and slave system (17) under the following conditions:

(i) $M^{-1}$ is bounded.

(ii) $\widehat{U}=M^{-1}(L e(t)+T)$ and $u_{4}=0$.

(iii) The feedback gain matrix $L \in \mathbf{R}^{3 \times 3}$ is selected such that $(A-L)^{T}+(A-L)$ is a negative definite matrix.

Proof. By substituting the control law (ii) into (22), the error system can be written as

$$
\dot{e}(t)=(A-L) e(t) .
$$

Construct the candidate Lyapunov function in the form $V(e(t))=e^{T}(t) e(t)$, and we obtain

$$
\begin{aligned}
\dot{V}(e(t)) & =\dot{e}^{T}(t) e(t)+e^{T}(t) \dot{e}(t) \\
& =e^{T}(t)(A-L)^{T} e(t)+e^{T}(t)(A-L) e(t) \\
& =e^{T}(t)\left[(A-L)^{T}+(A-L)\right] e(t) .
\end{aligned}
$$

Using (iii), then we get $\dot{V}(e(t))<0$. From Lemma 1 , the zero solution of error system (24) is globally asymptotically stable and therefore, master system (16) the slave system (17) are globally synchronized.

\section{Numerical Examples}

In this section, two numerical examples are considered to validate the proposed chaos synchronization schemes.

4.1. Example 1. Her, in this example, as the master system we consider the chaotic Chen system [57] and the controlled fractional hyperchaotic Liu system [58] as the slave system. The master system is defined as

$$
\begin{aligned}
& \dot{x}_{1}=\alpha\left(x_{2}-x_{1}\right), \\
& \dot{x}_{2}=(\gamma-\alpha) x_{1}+\gamma x_{2}-x_{1} x_{3}, \\
& \dot{x}_{3}=\beta x_{3}+x_{1} x_{2},
\end{aligned}
$$

where $x_{i}, i=1,2,3$, are the states of the master system. System (26) has a chaotic behavior when $\alpha=35, \beta=-3$, and $\gamma=28$. Chaotic attractors of master system (26) are shown in Figure 1. 


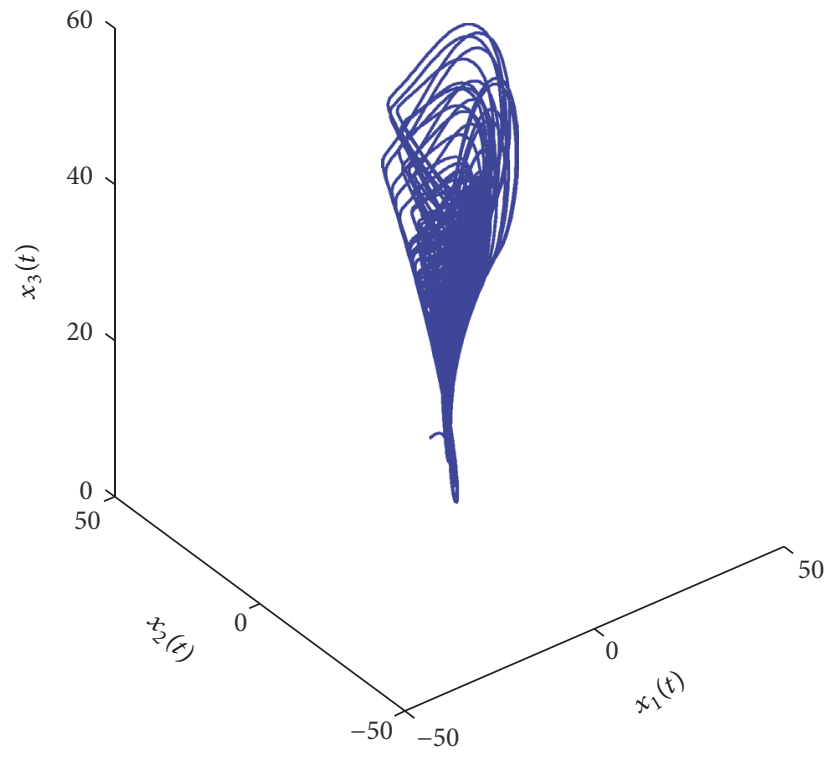

(a)

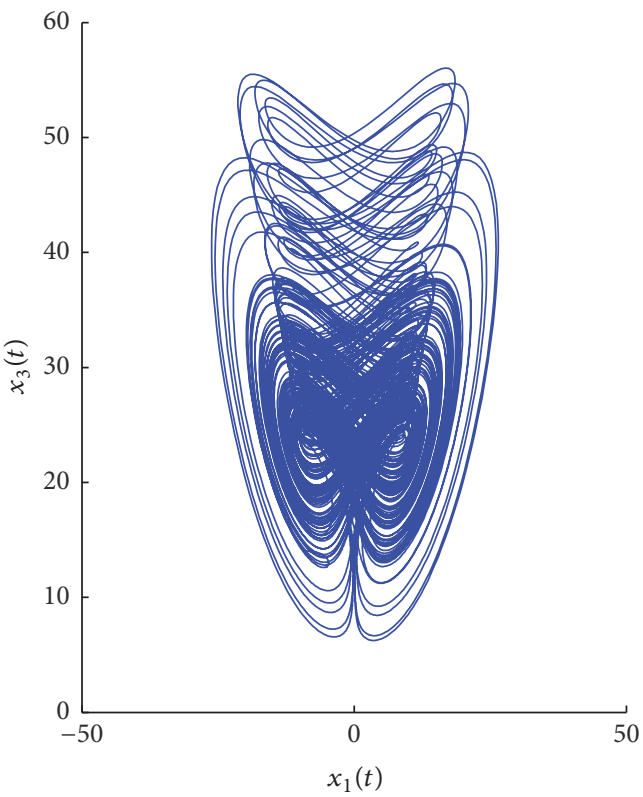

(c)

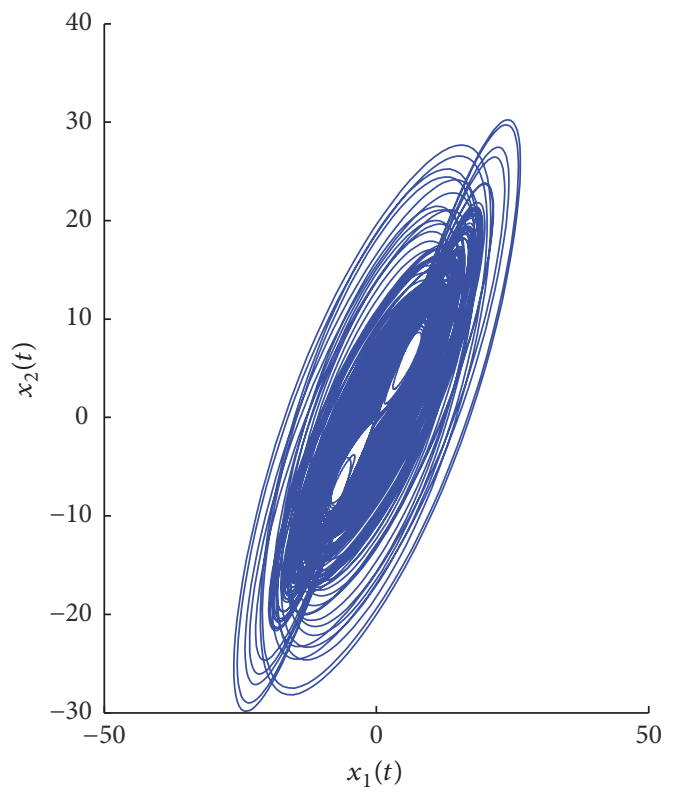

(b)

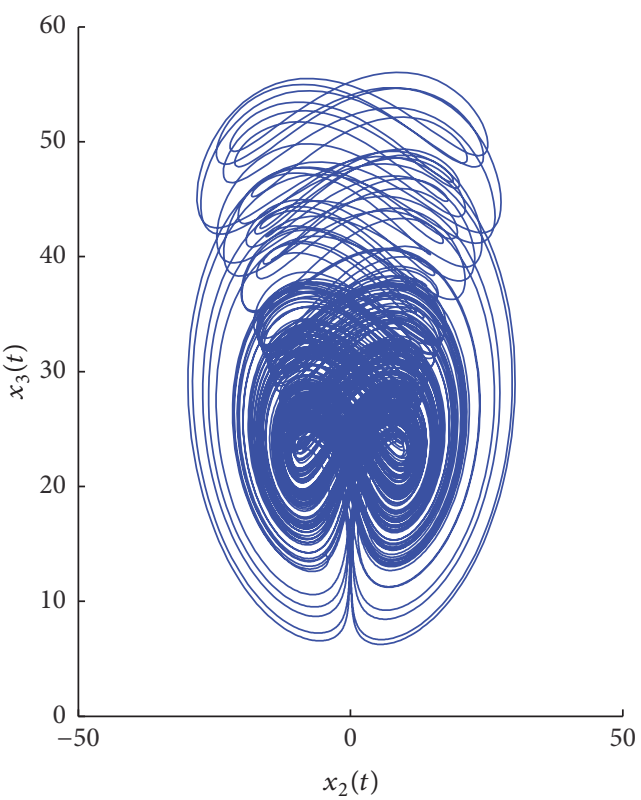

(d)

FIGURE 1: 3D and 2D chaotic attractors of Chen system (26).

The slave system is described by

$$
\begin{aligned}
& D^{q} y_{1}=b_{1}\left(y_{2}-y_{1}\right)+y_{4}+u_{1}, \\
& D^{q} y_{2}=b_{2} y_{1}+0.5 y_{4}-y_{1} y_{3}+u_{2}, \\
& D^{q} y_{3}=-b_{3} y_{3}-y_{4}+4 y_{1}^{2}+u_{3}, \\
& D^{q} y_{4}=-b_{4} y_{2}-y_{4}+u_{4},
\end{aligned}
$$

where $y_{i}, i=1,2,3,4$, are the states of the slave system and $U=\left(u_{i}\right)_{1<i<4}$ is the vector controller. This system, as shown in [58], exhibits hyperchaotic behavior when $\left(u_{1}, u_{2}, u_{3}, u_{4}\right)=$ $(0,0,0,0),\left(b_{1}, b_{2}, b_{3}, b_{4}\right)=(10,40,2.5,10 / 15)$, and $q=0.9$. The projections of the hyperchaotic Lorenz attractor are shown in Figure 2.

Comparing system (27) with system (6), we get

$$
B=\left(b_{i j}\right)_{4 \times 4}=\left(\begin{array}{cccc}
-10 & 10 & 0 & 1 \\
40 & 0 & 0 & 0.5 \\
0 & 0 & -2.5 & -1 \\
0 & -\frac{10}{15} & 0 & -1
\end{array}\right) \text {, }
$$





FIGURE 2: 3D phase portraits of the fractional hyperchaotic Liu system.

$$
\left(g_{i}\right)_{1 \leq i \leq 4}=\left(\begin{array}{c}
0 \\
-y_{1} y_{3} \\
4 y_{1}^{2} \\
0
\end{array}\right) \text {. }
$$

$$
\begin{aligned}
& e_{3}=y_{3}-\sum_{j=1}^{3} \beta_{j}(t) x_{j}, \\
& e_{4}=y_{4}-\varphi\left(x_{1}, x_{2}, x_{3}\right),
\end{aligned}
$$

Using the notations described in Section 3.1, the errors between master system (26) and slave system (27) are defined as

$$
\begin{aligned}
& e_{1}=y_{1}-x_{1}, \\
& e_{2}=y_{2}-\alpha x_{2},
\end{aligned}
$$

where $\alpha=2, \beta_{1}(t)=t, \beta_{2}(t)=t^{2}, \beta_{3}(t)=t^{3}$, and $\varphi\left(x_{1}, x_{2}\right.$, $\left.x_{3}\right)=x_{1} x_{2} x_{3}$. According to Theorem 5, the control law $\left(u_{1}\right.$, $\left.u_{2}, u_{3}, u_{4}\right)^{T}$ can be designed as

$$
\left(u_{1}, u_{2}, u_{3}, u_{4}\right)^{T}=-R-C \times\left(e_{1}, e_{2}, e_{3}, e_{4}\right)^{T},
$$



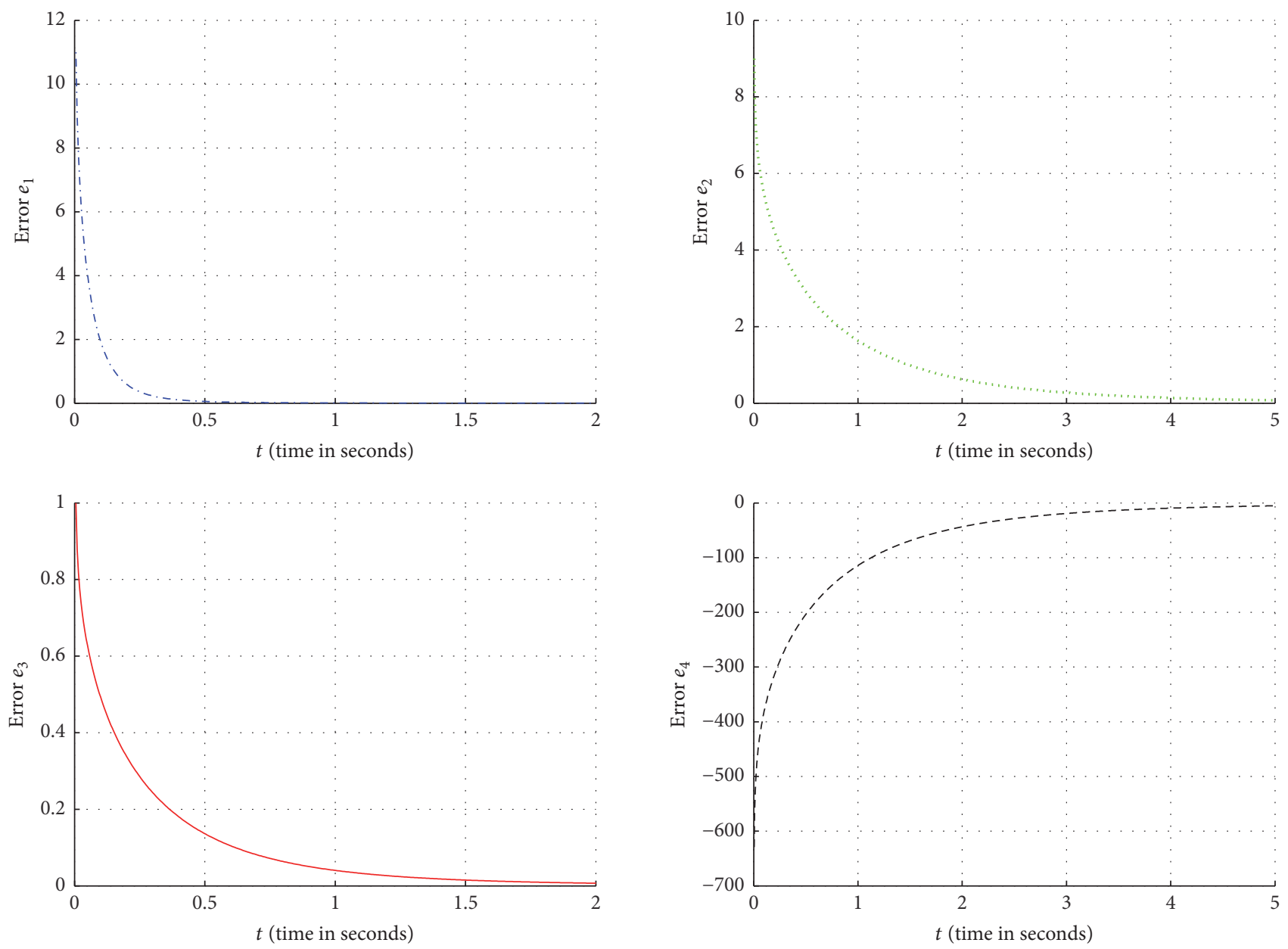

FIGURE 3: Time evolution of the synchronization errors $e_{1}, e_{2}, e_{3}$, and $e_{4}$ between master system (26) and slave system (27).

where

$$
\begin{aligned}
R_{1}= & -10\left(y_{1}-e_{1}\right)+10\left(y_{2}-e_{2}\right)+y_{4}-e_{4}-D^{0.9} x_{1}, \\
R_{2}= & 40\left(y_{1}-e_{1}\right)+0.5\left(y_{4}-e_{4}\right)-y_{1} y_{3} \\
& -2 D^{0.9} x_{2}(t) \\
R_{3}= & -2.5\left(y_{3}-e_{3}\right)-\left(y_{4}-e_{4}\right)+4 y_{1}^{2} \\
& -D^{0.9}\left(t x_{1}+t^{2} x_{2}+t^{3} x_{3}\right) \\
R_{4}= & -\frac{10}{15}\left(y_{2}-e_{2}\right)-\left(y_{4}-e_{4}\right)-D^{0.9}\left(x_{1} x_{2} x_{3}\right),
\end{aligned}
$$

and $C$ is a feedback gain matrix selected as

$$
C=\left(\begin{array}{cccc}
0 & 10 & 0 & 1 \\
40 & 1 & 0 & 0.5 \\
0 & 0 & 0 & -1 \\
0 & -\frac{10}{15} & 0 & 0
\end{array}\right)
$$

It is easy to show that $B-C$ is a negative definite matrix. Hence, the synchronization between master system (26) and slave system (27) is achieved and the error system can be described as follows:

$$
\begin{aligned}
& D^{0.9} e_{1}=-10 e_{1}, \\
& D^{0.9} e_{2}=-e_{2}, \\
& D^{0.9} e_{3}=-2.5 e_{3}, \\
& D^{0.9} e_{4}=-e_{4} .
\end{aligned}
$$

For the purpose of numerical simulation, the fractional Euler integration method has been used to solve system (33). The initial values of the master and the slave systems are $\left[x_{1}(0), x_{2}(0), x_{3}(0)\right]=[-9,-5,14]$ and $\left[y_{1}(0), y_{2}(0), y_{3}(0)\right.$, $\left.y_{4}(0)\right]=[2,-1,1,1]$, respectively, and the initial states of error system $(33)$ are $\left[e_{1}(0), e_{2}(0), e_{3}(0), e_{4}(0)\right]=[11,9,1$, $-629]$. Figure 3 displays the synchronization errors between systems (26) and (27).

4.2. Example 2. Now, in this example, as the master system we consider the fractional Lü system and the controlled 


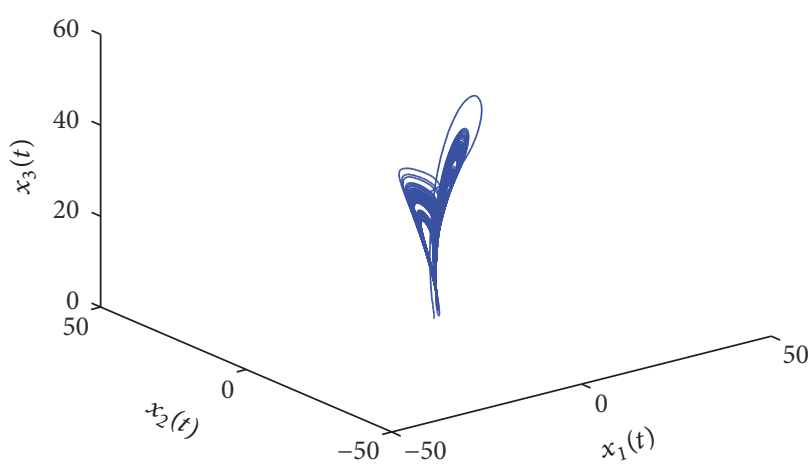

(a)

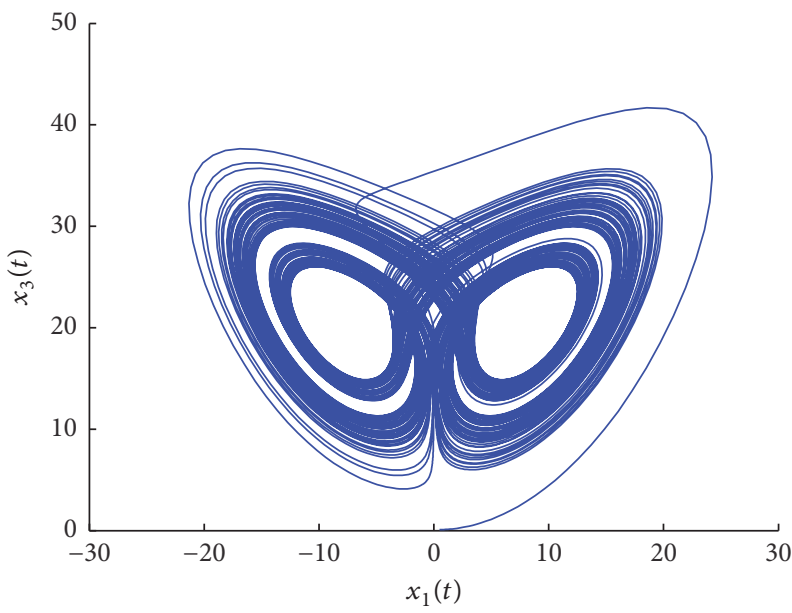

(c)

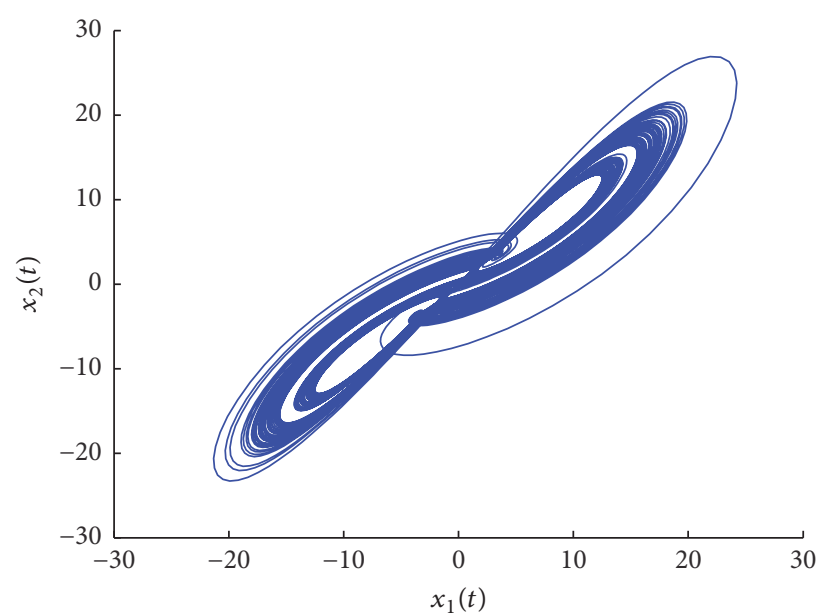

(b)

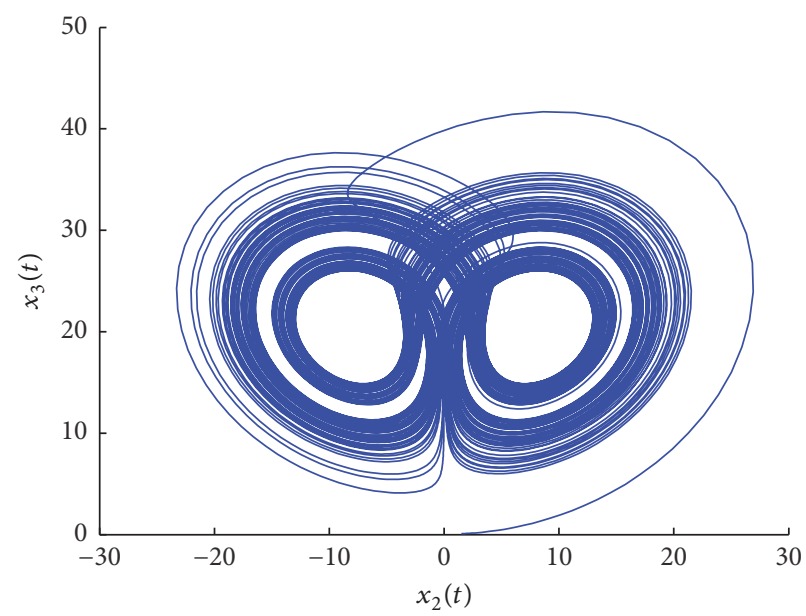

(d)

FIGURE 4: 3D and 2D chaotic attractors of fractional system (26).

hyperchaotic system, proposed by Zhang and Shen in [59], as the slave system. The master system is defined as

$$
\begin{aligned}
& D^{p_{1}} x_{1}=\alpha\left(x_{2}-x_{1}\right), \\
& D^{p_{2}} x_{2}=\gamma x_{2}-x_{1} x_{3}, \\
& D^{p_{3}} x_{3}=-\beta x_{3}+x_{1} x_{2} .
\end{aligned}
$$

It is found, in [60], that this system displays chaotic attractors when $(\alpha, \beta, \gamma)=(36,3,20)$ and $\left(p_{1}, p_{2}, p_{3}\right)=$ $(0.985,0.99,0.98)$. Chaotic attractors of master system (34) are shown in Figure 4.

Comparing system (34) with system (16), one can have

$$
A=\left(a_{i j}\right)=\left(\begin{array}{ccc}
-36 & 36 & 0 \\
0 & 20 & 0 \\
0 & 0 & -3
\end{array}\right) \text {, }
$$

$$
\left(f_{i}\right)_{1 \leq i \leq 3}=\left(\begin{array}{c}
0 \\
-x_{1} x_{3} \\
x_{1} x_{2}
\end{array}\right) .
$$

The slave system is described by

$$
\begin{aligned}
& \dot{y}_{1}=a y_{1}-y_{2}+u_{1}, \\
& \dot{y}_{2}=y_{1}-y_{2} y_{3}^{2}+u_{2}, \\
& \dot{y}_{3}=b y_{3}-y_{2}-6 y_{4}+u_{3}, \\
& \dot{y}_{4}=y_{3}+c y_{4}+u_{4} .
\end{aligned}
$$

The 4D Zhang-Shen system, that is, system (36) with $u_{1}=u_{2}=u_{3}=u_{4}=0$, exhibits hyperchaotic behavior when $(a, b, c)=(0.56,-1,0.8)$. Chaotic attractors in $3 \mathrm{D}$ of the uncontrolled system (36) are shown in Figure 5. 

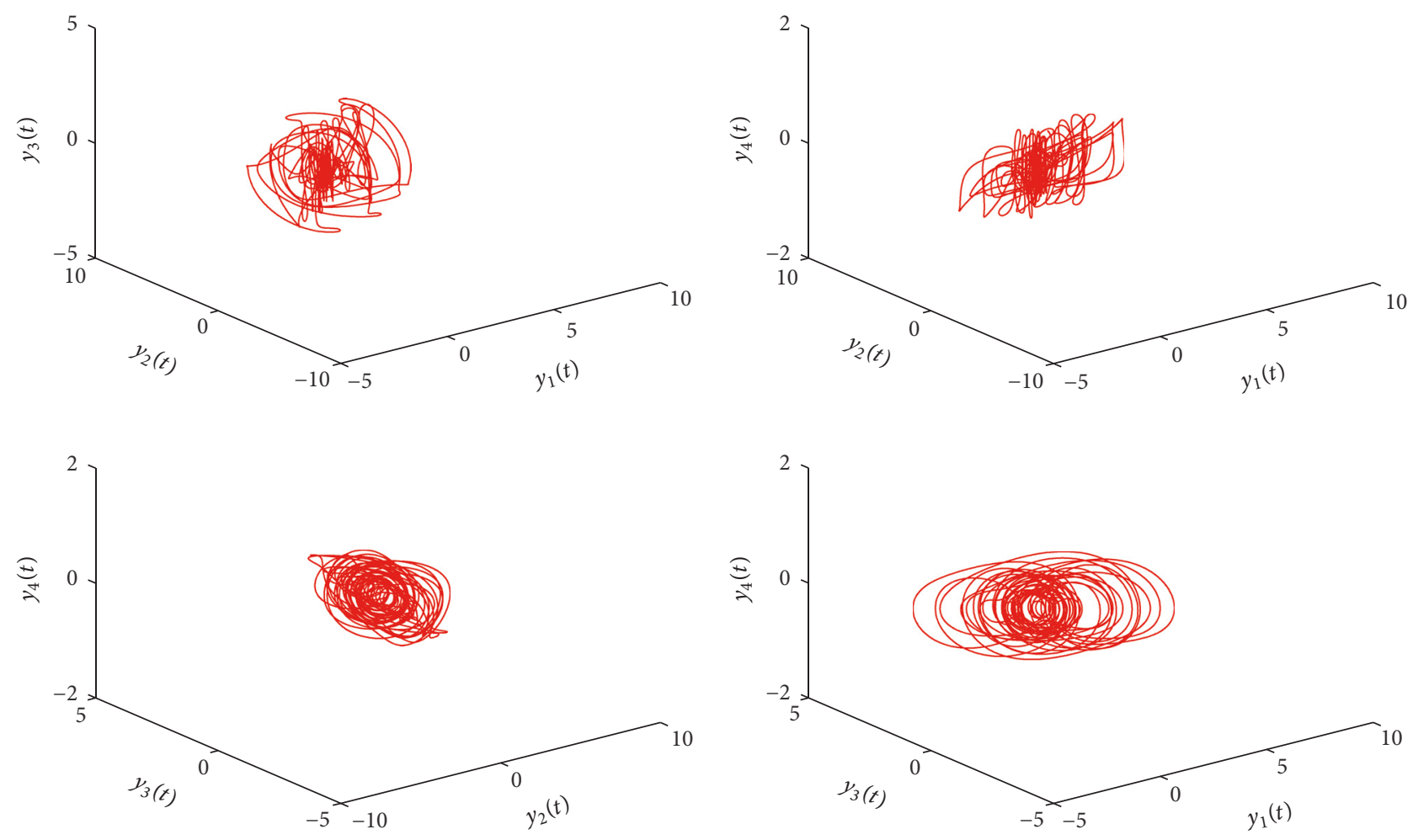

FIGURE 5: 3D phase portraits of the hyperchaotic Zhang-Shen system.

Based on the notations presented in Section 3.2, the errors between master system (34) and slave system (36) are given as

$$
\begin{aligned}
& e_{1}=x_{1}-h(t) y_{1}, \\
& e_{2}=x_{2}-\sum_{j=1}^{4} \Lambda_{j}(t) y_{j}, \\
& e_{3}=x_{3}-\phi\left(y_{1}, y_{2}, y_{3}, y_{4}\right),
\end{aligned}
$$

where $h(t)=t^{2}+1, \Lambda_{1}(t)=0, \Lambda_{2}(t)=\exp (t), \Lambda_{3}(t)=0$, $\Lambda_{4}(t)=t^{4}$, and $\phi\left(y_{1}, y_{2}, y_{3}, y_{4}\right)=3 y_{3}+y_{4}^{2}$. So, the matrix $M$ defined by (23) is

$$
M=\left(\begin{array}{ccc}
t^{2}+1 & 0 & 0 \\
0 & \exp (t) & 0 \\
0 & 0 & 3
\end{array}\right)
$$

According to Theorem 7 , the control law $\left(u_{1}, u_{2}, u_{3}, u_{4}\right)^{\mathrm{T}}$ can be constructed as

$$
\begin{aligned}
\left(u_{1}, u_{2}, u_{3}\right)^{T} & =M^{-1}\left[T+L\left(e_{1}, e_{2}, e_{3}\right)^{T}\right], \\
u_{4} & =0,
\end{aligned}
$$

where

$$
\begin{aligned}
M^{-1}= & \left(\begin{array}{ccc}
\frac{1}{t^{2}+1} & 0 & 0 \\
0 & \exp (-t) & 0 \\
0 & 0 & \frac{1}{3}
\end{array}\right), \\
T_{1}= & \dot{x}_{1}+36 e_{1}-36 e_{2}-2 t y_{1} \\
& -\left(t^{2}+1\right)\left(0.56 y_{1}-y_{2}\right), \\
T_{2}= & \dot{x}_{2}-20 e_{2}-\exp (t) y_{2}-4 t^{3} y_{4} \\
& -\exp (t)\left(y_{1}-y_{2} y_{3}^{2}\right)-t^{4}\left(y_{3}+0.8 y_{4}\right), \\
T_{3}= & \dot{x}_{3}+3 e_{3}+3\left(y_{3}+y_{2}+6 y_{4}\right) \\
& -2 y_{4}\left(y_{3}+0.8 y_{4}\right), \\
L= & \left(\begin{array}{lll}
0 & 36 & 0 \\
0 & 30 & 0 \\
0 & 0 & 0
\end{array}\right) .
\end{aligned}
$$

We can see that $(A-L)^{T}+(A-L)$ is a negative definite matrix. Hence, the synchronization between master system 

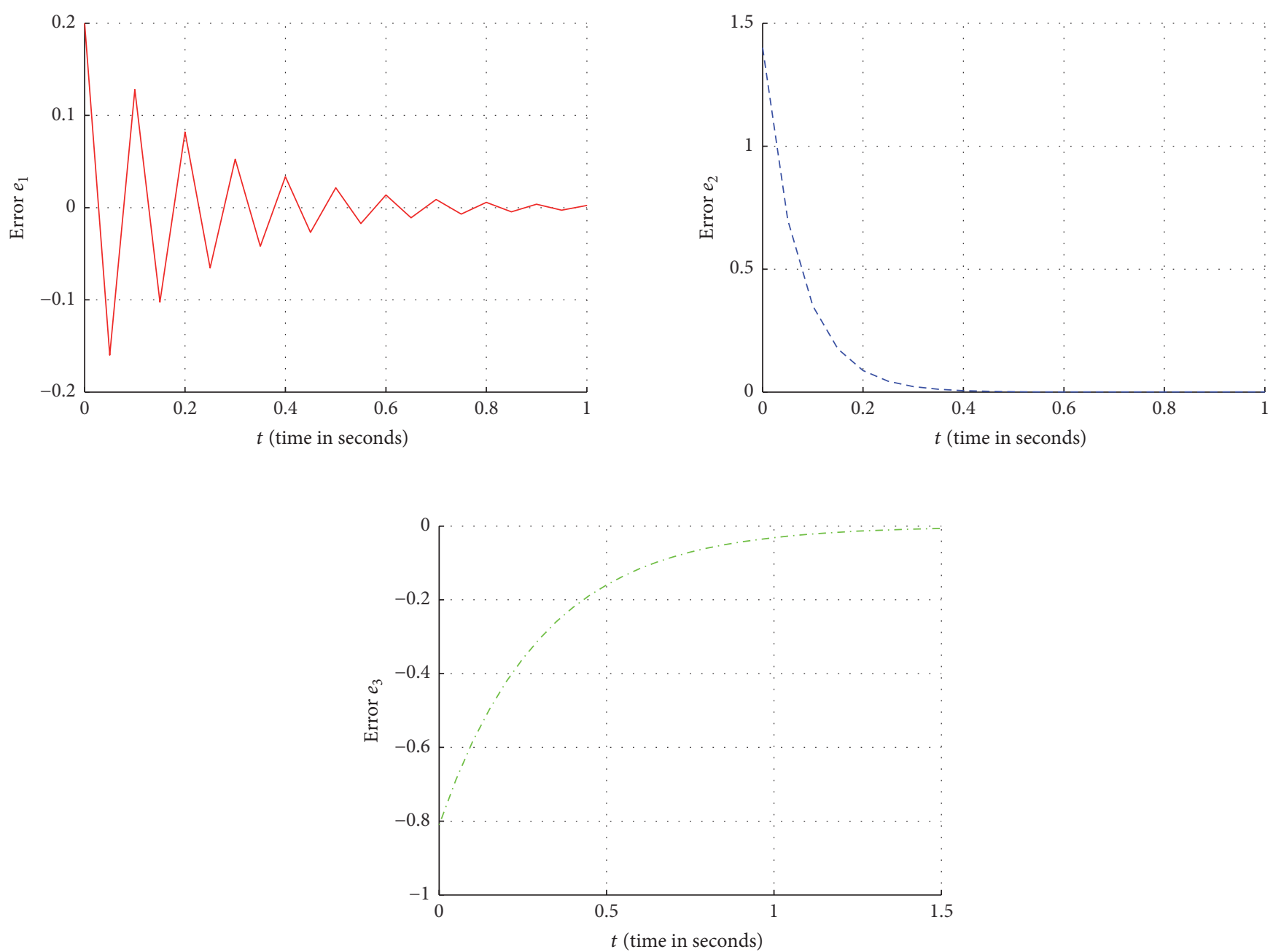

FIGURE 6: Time evolution of the synchronization errors $e_{1}, e_{2}$, and $e_{3}$ between master system (34) and slave system (36).

(34) and slave system (36) is achieved and the error system can be described as

$$
\begin{aligned}
& \dot{e}_{1}=-36 e_{1}, \\
& \dot{e}_{2}=-10 e_{2}, \\
& \dot{e}_{3}=-3 e_{3} .
\end{aligned}
$$

For the purpose of numerical simulation, the fourth order Runge-Kutta integration method has been used to solve system (41). The initial values of the master and the slave systems are $\left[x_{1}(0), x_{2}(0), x_{3}(0)\right]=[0.5,1.5,0.1]$ and $\left[y_{1}(0), y_{2}(0), y_{3}(0), y_{4}(0)\right]=[0.7,0.1,0.3,0.1]$, respectively, and the initial states of the error system are $\left[e_{1}(0), e_{2}(0), e_{3}(0)\right]=[0.2,1.4,-0.81]$. Figure 6 displays the synchronization errors between systems (34) and (36).

\section{Conclusion}

This paper has presented new schemes to study the coexistence of some types of chaos synchronization between nonidentical and different dimensional master and slave systems described by integer order and fractional order differential equations. The first scheme was constructed by combining CS, PS, FSHFPS, and GS in the synchronization of 3D integer order master system and 4D fractional order slave system. The second one was proposed when IPS, IFSHFPS, and IGS coexist between 3D fractional order master system and 4D integer order slave system. By exploiting fractional order Lyapunov approach and integer order Lyapunov method, the proposed synchronization approaches were rigorously proved to be achievable. The capability of the methods was illustrated by numerical examples and computer simulations.

\section{Conflicts of Interest}

The authors declare that there are no conflicts of interest regarding the publication of this paper.

\section{Acknowledgments}

The author Xiong Wang was supported by the National Natural Science Foundation of China (no. 61601306) and 
Shenzhen Overseas High Level Talent Peacock Project Fund (no. 20150215145C).

\section{References}

[1] D. Cafagna and G. Grassi, "Fractional-order systems without equilibria: the first example of hyperchaos and its application to synchronization," Chinese Physics B, vol. 24, no. 8, Article ID 080502, 2015.

[2] Y. Gao, C. Liang, Q. Wu, and H. Yuan, "A new fractional-order hyperchaotic system and its modified projective synchronization," Chaos, Solitons \& Fractals, vol. 76, pp. 190-204, 2015.

[3] A. M. El-Sayed, H. M. Nour, A. Elsaid, A. E. Matouk, and A. Elsonbaty, "Dynamical behaviors, circuit realization, chaos control, and synchronization of a new fractional order hyperchaotic system," Applied Mathematical Modelling. Simulation and Computation for Engineering and Environmental Systems, vol. 40, no. 5-6, pp. 3516-3534, 2016.

[4] J. Zhang, J. Nan, W. Du, Y. Chu, and H. Luo, "Dynamic analysis for a fractional-order autonomous chaotic system," Discrete Dynamics in Nature and Society, vol. 2016, Article ID 8712496, 13 pages, 2016.

[5] K. Rajagopal, L. Guessas, A. Karthikeyan, A. Srinivasan, and G. Adam, "Fractional order memristor no equilibrium chaotic system with its adaptive sliding mode synchronization and genetically optimized fractional order PID synchronization," Complexity, vol. 2017, Article ID 1892618, 19 pages, 2017.

[6] F. Zhang, G. Chen, C. Li, and J. Kurths, "Chaos synchronization in fractional differential systems," Philosophical Transactions of the Royal Society of London. Series A. Mathematical, Physical and Engineering Sciences, vol. 371, no. 1990, 26 pages, 2013.

[7] P. Muthukumar, P. Balasubramaniam, and K. Ratnavelu, "Sliding mode control design for synchronization of fractional order chaotic systems and its application to a new cryptosystem," International Journal of Dynamics and Control, vol. 5, no. 1, pp. 115-123, 2017.

[8] A. E. Matouk, "Chaos synchronization of a fractional-order modified van der Pol-Duffing system via new linear control, backstepping control and Takagi-Sugeno fuzzy approaches," Complexity, vol. 21, no. S1, pp. 116-124, 2016.

[9] R. Behinfaraz and M. Badamchizadeh, "Optimal synchronization of two different in-commensurate fractional-order chaotic systems with fractional cost function," Complexity, vol. 21, no. S1, pp. 401-416, 2016.

[10] A. Ouannas, M. M. Al-sawalha, and T. Ziar, "Fractional chaos synchronization schemes for different dimensional systems with non-identical fractional-orders via two scaling matrices," Optik, vol. 127, no. 20, pp. 8410-8418, 2016.

[11] W. S. Sayed, M. M. Henein, S. K. Abd-El-Hafiz, and A. G. Radwan, "Generalized dynamic switched synchronization between combinations of fractional-order chaotic systems," Complexity, vol. 2017, Article ID 9189120, 17 pages, 2017.

[12] A. Ouannas, G. Grassi, T. Ziar, and Z. Odibat, "On a function projective synchronization scheme for non-identical Fractional-order chaotic (hyperchaotic) systems with different dimensions and orders," Optik - International Journal for Light and Electron Optics, vol. 136, pp. 513-523, 2017.

[13] L. M. Pecora and T. L. Carroll, "Synchronization in chaotic systems," Physical Review Letters, vol. 64, no. 8, pp. 821-824, 1990.

[14] M. A. Aziz-Alaoui, "Synchronization of chaos," Encyclopedia of Mathematical Physics, vol. 5, pp. 213-226, 2006.
[15] A. C. Luo, "A theory for synchronization of dynamical systems," Communications in Nonlinear Science and Numerical Simulation, vol. 14, no. 5, pp. 1901-1951, 2009.

[16] P. Dong, G. Shang, and J. Liu, "Anticipating synchronization of integer order and fractional order hyper-chaotic Chen system," International Journal of Modern Physics B, vol. 26, no. 32, Article ID 1250211, 15 pages, 2012.

[17] Z. Ping and Y.-X. Cao, "Function projective synchronization between fractional-order chaotic systems and integer-order chaotic systems," Chinese Physics B, vol. 19, no. 10, Article ID 100507, 2010

[18] A. Khan and P. Tripathi, "Synchronization between a fractional order chaotic system and an integer order chaotic system," Nonlinear Dynamics and Systems Theory, vol. 13, no. 4, pp. 425436, 2013.

[19] Y. Wu and G. Wang, "Synchronization and antisynchronization between a class of fractional-order and integer-order chaotic systems with only one controller term," Journal of Theoretical \& Applied Information Technology, vol. 48, no. 1, pp. 145-151, 2013.

[20] A. Ouannas and R. Abu-Saris, "A robust control method for Q$S$ synchronization between different dimensional integer-order and fractional-order chaotic systems," Journal of Control Science and Engineering, vol. 2015, Article ID 703753, 7 pages, 2015.

[21] A. Ouannas and A. Karouma, "Different generalized synchronization schemes between integer-order and fractionalorder chaotic systems with different dimensions," Differential Equations and Dynamical Systems, pp. 1-13, 2016.

[22] L.-X. Jia, H. Dai, and M. Hui, "Nonlinear feedback synchronisation control between fractional-order and integer-order chaotic systems," Chinese Physics B, vol. 19, no. 11, Article ID 110509, 2010.

[23] Z. Ping, Y.-M. Cheng, and K. Fei, "Synchronization between fractional-order chaotic systems and integer orders chaotic systems (fractional-order chaotic systems)," Chinese Physics B, vol. 19, no. 9, Article ID 090503, 2010.

[24] L.-X. Yang, W.-S. He, and X.-J. Liu, "Synchronization between a fractional-order system and an integer order system," Computers \& Mathematics with Applications, vol. 62, no. 12, pp. 47084716, 2011.

[25] G.-Q. Si, Z.-Y. Sun, and Y.-B. Zhang, "A general method for synchronizing an integer-order chaotic system and a fractionalorder chaotic system," Chinese Physics B, vol. 20, no. 8, Article ID 080505, 2011.

[26] D. Chen, R. Zhang, J. Clinton Sprott, and X. Ma, "Synchronization between integer-order chaotic systems and a class of fractional-order chaotic system based on fuzzy sliding mode control," Nonlinear Dynamics. An International Journal of Nonlinear Dynamics and Chaos in Engineering Systems, vol. 70, no. 2, pp. 1549-1561, 2012.

[27] D.-Y. Chen, R.-F. Zhang, X.-Y. Ma, and J. Wang, "Synchronization between a novel class of fractional-order and integer-order chaotic systems via a sliding mode controller," Chinese Physics $B$, vol. 21, no. 12, Article ID 120507, 2012.

[28] Y.-P. Wu and G.-D. Wang, "Synchronization between fractionalorder and integer-order hyperchaotic systems via sliding mode controller," Journal of Applied Mathematics, vol. 2013, Article ID 151025, 5 pages, 2013.

[29] Y. Wu and G. Wang, "Synchronization of a class of fractionalorder and integer order hyperchaotic systems," Journal of Vibration and Control, vol. 20, no. 10, pp. 1584-1588, 2014. 
[30] D. Chen, C. Wu, H. H. Iu, and X. Ma, "Circuit simulation for synchronization of a fractional-order and integer-order chaotic system," Nonlinear Dynamics. An International Journal of Nonlinear Dynamics and Chaos in Engineering Systems, vol. 73, no. 3, pp. 1671-1686, 2013.

[31] I. E. Gammoudi and M. Feki, "Synchronization of integer order and fractional order Chua's systems using robust observer," Communications in Nonlinear Science and Numerical Simulation, vol. 18, no. 3, pp. 625-638, 2013.

[32] S. Vaidyanathan, "Complete synchronization of hyperchaotic $\mathrm{Xu}$ and hyperchaotic Lü systems via active control," International Journal of Computer Science \& Engineering Survey, vol. 3, no. 3, pp. 29-43, 2012.

[33] S. P. Ansari and S. Das, "Projective synchronization of timedelayed chaotic systems with unknown parameters using adaptive control method," Mathematical Methods in the Applied Sciences, vol. 38, no. 4, pp. 726-737, 2015.

[34] G. Cai, L. Yao, P. Hu, and X. Fang, "Adaptive full state hybrid function projective synchronization of financial hyperchaotic systems with uncertain parameters," Discrete and Continuous Dynamical Systems. Series B. A Journal Bridging Mathematics and Sciences, vol. 18, no. 8, pp. 2019-2028, 2013.

[35] S.-Y. Li, S.-A. Chen, C.-T. Lin, L.-W. Ko, C.-H. Yang, and H.-H. Chen, "Generalized synchronization of nonlinear chaotic systems through natural bioinspired controlling strategy," Abstract and Applied Analysis, Article ID 725674, 14 pages, 2015.

[36] A. Razminia and D. Baleanu, "Complete synchronization of commensurate fractional order chaotic systems using sliding mode control," Mechatronics, vol. 23, no. 7, pp. 873-879, 2013.

[37] S. K. Agrawal and S. Das, "Projective synchronization between different fractional-order hyperchaotic systems with uncertain parameters using proposed modified adaptive projective synchronization technique," Mathematical Methods in the Applied Sciences, vol. 37, no. 14, pp. 2164-2176, 2014.

[38] L. Zhang and T. Liu, "Full state hybrid projective synchronization of variable-order fractional chaotic/hyperchaotic systems with nonlinear external disturbances and unknown parameters," Journal of Nonlinear Science and its Applications. JNSA, vol. 9, no. 3, pp. 1064-1076, 2016.

[39] R. Martínez-Guerra and J. L. Mata-Machuca, "Fractional generalized synchronization in a class of nonlinear fractional order systems," Nonlinear Dynamics. An International Journal of Nonlinear Dynamics and Chaos in Engineering Systems, vol. 77, no. 4, pp. 1237-1244, 2014.

[40] G. Ahlem and A. Ouannas, "A general control method for inverse hybrid function projective synchronization of a class of chaotic systems," International Journal of Mathematical Analysis, vol. 9, no. 9-12, pp. 429-436, 2015.

[41] A. Ouannas and G. Grassi, "Inverse full state hybrid projective synchronization for chaotic maps with different dimensions," Chinese Physics B, vol. 25, no. 9, Article ID 090503, 2016.

[42] A. Ouannas, A. T. Azar, and T. Ziar, "On inverse full state hybrid function projective synchronization for continuoustime chaotic dynamical systems with arbitrary dimensions," Differential Equations and Dynamical Systems, pp. 1-14, 2017.

[43] A. Ouannas and Z. Odibat, "On inverse generalized synchronization of continuous chaotic dynamical systems," International Journal of Applied and Computational Mathematics, vol. 2, no. 1, pp. 1-11, 2016.

[44] A. Ouannas and G. Grassi, "A new approach to study the coexistence of some synchronization types between chaotic maps with different dimensions," Nonlinear Dynamics, vol. 86, no. 2 , pp. 1319-1328, 2016.

[45] A. Ouannas, A. T. Azar, and S. Vaidyanathan, "New hybrid synchronisation schemes based on coexistence of various types of synchronisation between master-slave hyperchaotic systems," International Journal of Computer Applications in Technology, vol. 55, no. 2, p. 112, 2017.

[46] A. Ouannas, A. T. Azar, and S. Vaidyanathan, "A robust method for new fractional hybrid chaos synchronization," Mathematical Methods in the Applied Sciences, vol. 40, no. 5, pp. 1804-1812, 2017.

[47] A. Ouannas, S. Abdelmalek, and S. Bendoukha, "Co-existence of some chaos synchronization types in fractiona-order differential equations," Electronic Journal of Differential Equations, vol. 2017, no. 5, pp. 1804-1812, 2017.

[48] K. B. Oldham and J. Spanier, The Fractional Calculus, Academic Press, New York, NY, USA, 1974.

[49] R. Gorenflo and F. Mainardi, "Fractional calculus: integral and differential equations of fractional order," in Fractals and Fractional Calculus in Continuum Mechanics, A. Carpinteri and F. Mainardi, Eds., pp. 223-276, Springer, New York, NY, USA, 1997.

[50] M. Caputo, "Linear Models of Dissipation whose Q is almost Frequency Independent-II," Geophysical Journal of the Royal Astronomical Society, vol. 13, no. 5, pp. 529-539, 1967.

[51] S. G. Samko, A. A. Kilbas, and O. I. Marichev, Fractional Integrals and Derivatives, Theory and Applications, Gordon and Breach, Amsterdam, 1993.

[52] A. A. Kilbas, H. M. Srivastava, and J. J. Trujillo, Theory and Applications of Fractional Differential Equations, Elsevier, 2006.

[53] I. Podlubny and S. G. Samko, Fractional Differential Equations, vol. 198 of Mathematics in Science and Engineering, Academic Press, San Diego, Calif, USA, 1999.

[54] S. Wiggins, Introduction to Applied Nonlinear Dynamical Systems and Chaos, Springer, New York, NY, USA, 2003.

[55] D. Chen, R. Zhang, X. Liu, and X. Ma, "Fractional order Lyapunov stability theorem and its applications in synchronization of complex dynamical networks," Communications in Nonlinear Science and Numerical Simulation, vol. 19, no. 12, pp. 4105-4121, 2014.

[56] N. Aguila-Camacho, M. A. Duarte-Mermoud, and J. A. Gallegos, "Lyapunov functions for fractional order systems," Communications in Nonlinear Science and Numerical Simulation, vol. 19, no. 9, pp. 2951-2957, 2014.

[57] G. Chen and T. Ueta, "Yet another chaotic attractor," International Journal of Bifurcation and Chaos in Applied Sciences and Engineering, vol. 9, no. 7, pp. 1465-1466, 1999.

[58] Q. Han, C.-X. Liu, L. Sun, and D.-R. Zhu, "A fractional order hyperchaotic system derived from a Liu system and its circuit realization," Chinese Physics B, vol. 22, no. 2, Article ID 020502, 2013.

[59] X. Zhang and K. Shen, "The control action of the periodic perturbation on a hyperchaotic system," Acta Physica Sinica, vol. 8, no. 9, pp. 651-656, 1999.

[60] W. H. Deng and C. P. Li, "Chaos synchronization of the fractional Lü system," Physica A: Statistical Mechanics and Its Applications, vol. 353, no. 1-4, pp. 61-72, 2005. 


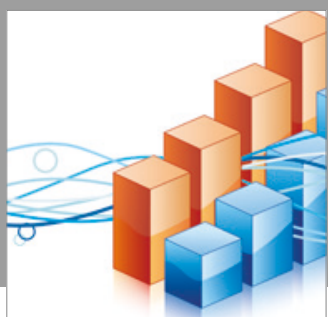

Advances in

Operations Research

vatersals

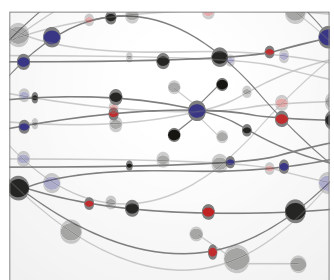

\section{The Scientific} World Journal
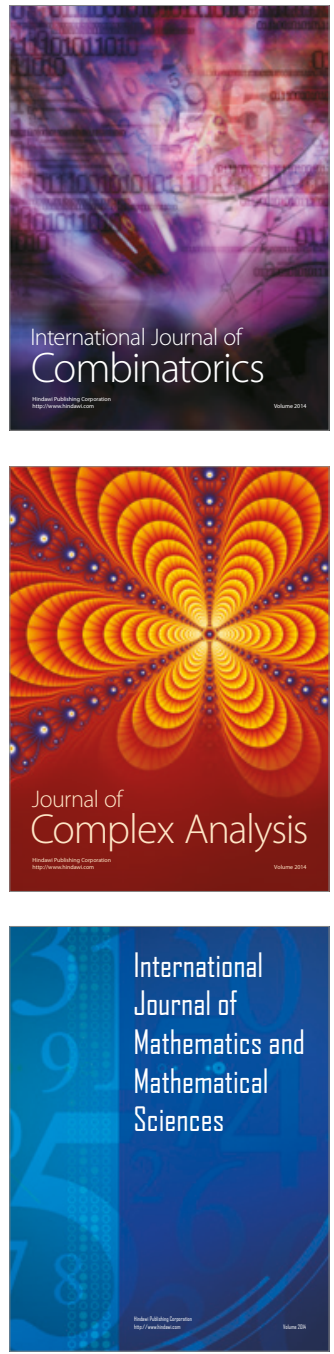
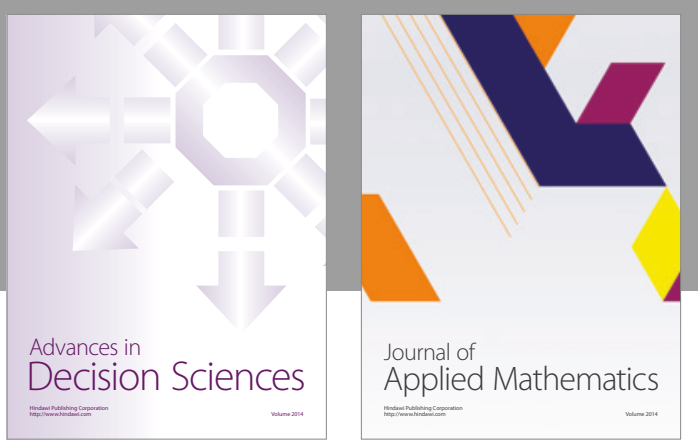

Algebra

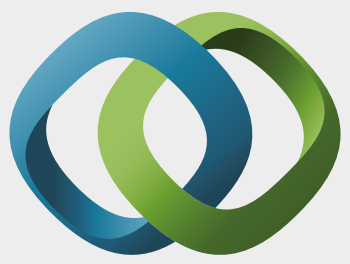

\section{Hindawi}

Submit your manuscripts at

https://www.hindawi.com




Mathematical Problems in Engineering
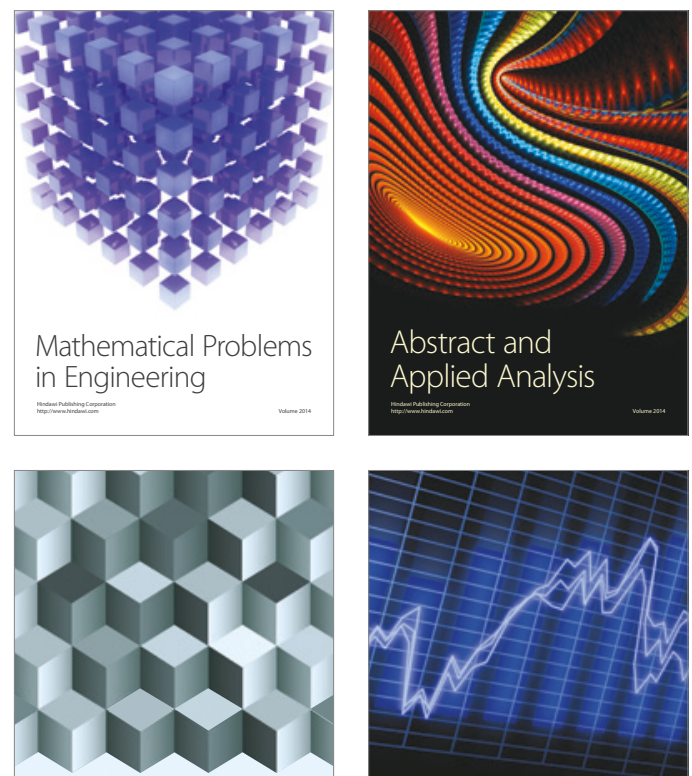

Journal of

Function Spaces

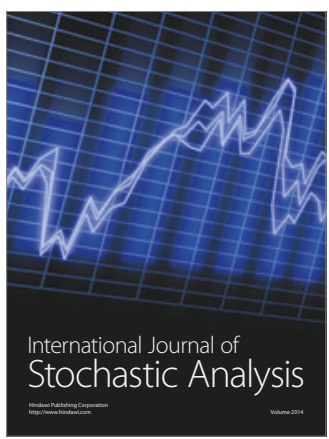

Probability and Statistics
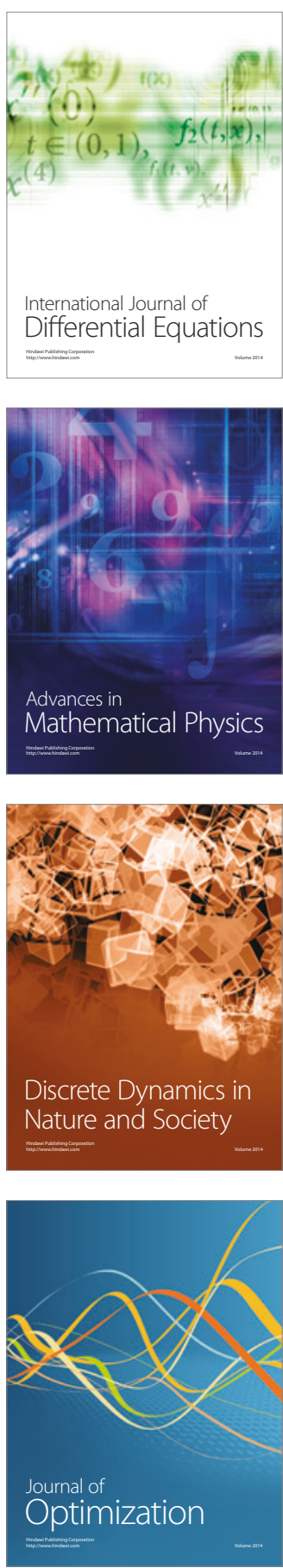